\title{
Pycnodysostosis with the focus on clinical and radiographic findings
}

Ben Barnard, $M B$ ChB

Department of Radiology, Kimberley Hospital Complex, Kimberley

\section{Wim Hiddema, $\mathbf{M B} \mathbf{C h B}$}

Department of Orthopaedics, Pelonomi Hospital, University of the Free State

Corresponding author: B Barnard (benwbarnard@gmail.com)

Pycnodyostosis is a rare autosomal recessive disorder that manifests as generalised osteosclerosis of the skeleton as a result of decreased bone turnover. Patients tend to suffer from numerous fractures owing to dense, abnormally brittle bones. The syndrome has a number of characteristic clinical and radiographic signs that differentiate it from other osteosclerotic conditions. This report is of a young man with a history of long bone fractures.

S Afr J Rad 2012;16(2):74-76

Pycnodyostosis is a rare genetic osteosclerotic disorder first described by Maroteaux and Lamy in $1962 \cdot .^{1-3}$ It is an autosomal recessive illness ${ }^{1-6}$ that manifests as generalised osteosclerosis of the skeleton as a result of decreased bone turnover. ${ }^{2}$ Patients present with multiple fractures owing to dense, abnormally brittle bones. Pycnodysostosis has a number of characteristic clinical and radiographic signs that differentiate it from other osteosclerotic conditions. Recognition of these signs is important in order to make the diagnosis and prevent possible complications.

\section{Case report}

Our patient was a 21-year-old man who presented to the Orthopaedic Outpatient Department with the complaint of a painful left lower leg following a minor fall 2 weeks prior to presentation. He also provided a history of multiple previous long bone fractures over the course of the previous 4 years, including bilateral femur fractures, bilateral tibia fractures and a right humerus fracture. All fractures were preceded by only minimally traumatic events and had been treated conservatively, with the exception of the femur fractures which were surgically managed with open reduction and internal fixatation. The rest of his past medical history was unremarkable.

On clinical examination, the patient demonstrated dysmorphic features with short stature and proportionately short limbs. He had a large head, with a small facial structure and jaw. Dental examination revealed a narrow palate, crooked teeth with overcrowding, as well as multiple caries. His lower limbs demonstrated angular deformities in keeping with the history of previous fractures. Extremities had short digits with dysplastic nails.

Bloodwork was normal, including serum calcium, magnesium and phosphate. No elevation of the alkaline phosphatase level was found.

The patient was sent for a plain film X-ray survey of his axial skeleton and limbs, including extremities. A subacute fracture of the midshaft of the left tibia was noted, with mild angulation and early callous formation. The rest of the long bones demonstrated clear osteosclerosis, with poorly formed but open medullary spaces. Evidence of previous fractures of both femurs as well as both tibias was noted. The previous tibia fractures had healed with anterior angular deformities.

Skull films showed a large cranial vault with persistent open fontanelles and wide sutures, as well as wormian bones. The maxilla was hypoplastic with non-pneumatisation of the frontal sinuses. The mandible was underdeveloped with an obtuse jaw angle.

The left acromion was underdeveloped, with a large acromioclavicular joint space. Spool-shaped thoracic and lumbar vertebral bodies were seen, with prominent anterior defects. A spondylolisthesis of L5 on S1 was also noted.

Films of the hands showed aplastic terminal phalanges in keeping with acro-osteolysis.

The characteristic clinical and radiological features exhibited by the patient led to a diagnosis of pycnodysostosis.

\section{Discussion}

Pycnodysostosis is a rare inherited disorder, with an incidence estimated to be 1.7 per million births. ${ }^{1,2}$ It was first described in 1962 by Maroteaux and Lamy as a form of dwarfism with craniofacial malformations similar to cleidocranial dysostosis. ${ }^{2}$ Other authors have labeled it the Toulouse-Lautrec syndrome, as the French painter Henri de ToulouseLautrec is claimed to have suffered from the disorder. ${ }^{2-4}$

Pycnodysostosis is an autosomal recessive disease ${ }^{1-6}$ characterised by systemic osteosclerosis owing to decreased bone turnover. During the 1990s, the genetic defect was located on chromosome 1q21 which led to specific genetic testing and accurate diagnosis. ${ }^{1,2}$ A mutation in the gene that codes for the enzyme cathepsin $\mathrm{K}$ inhibits the normal functioning of osteoclasts. Cathepsin $\mathrm{K}$ is a lysosomal cystine protease expressed in osteoclasts that is primarily responsible for degrading collagen type 1 (which forms $95 \%$ of the organic bone matrix). ${ }^{1,2,5}$ Defective osteoclasts cause impaired bone resorbtion and remodelling, which is essential for normal bone maintenance, both during growth and healing. Bones in affected individuals are therefore abnormally dense and brittle and easily fracture. ${ }^{1}$ Sparing of the medullary cavity within the long bones is characteristic of the disorder, resulting in normal haematopoietic function. ${ }^{1,2,4,5}$

The disorder is normally diagnosed at a young age owing to the characteristic phenotypical appearance with proportionate dwarfism and dysmorphic facies. ${ }^{2}$ It is, however (as in our case), sometimes diagnosed late, as a result of inclination to fractures and infections 


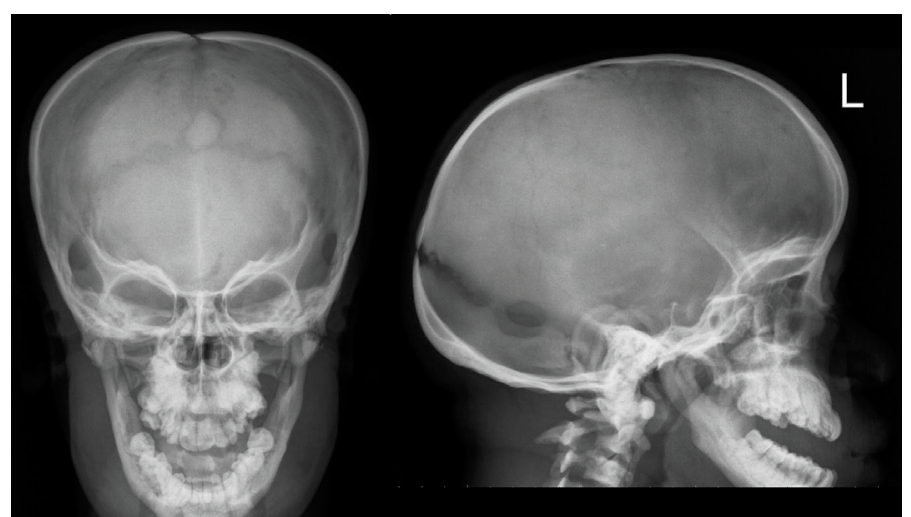

Fig. 1. AP and lateral skull $X$-rays reveal a large cranial vault with persistent open sutures and fontanelles as well as wormian bones. Hypoplastic facial bones with non-pneumatisation of the frontal sinuses and an underdeveloped mandible with an obtuse jaw angle are also demonstrated.

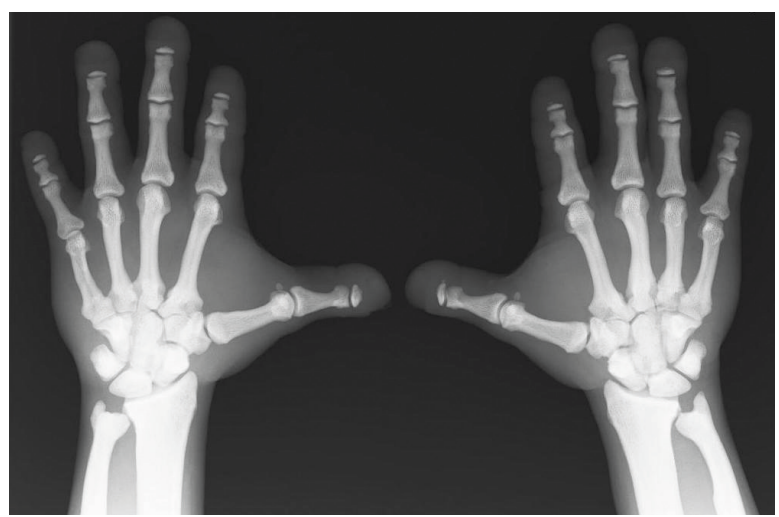

Fig. 2. AP X-ray of both hands demonstrate short stubby fingers with dysplastic nails and acro-osteolysis.

Table 1. Characteristic clinical and radiographic features of pycnodysostosis

\begin{tabular}{|c|c|c|}
\hline & Clinical features & Radiographic findings \\
\hline \multirow[t]{3}{*}{ General } & Short stature with proportionate dwarfism & Generalised osteosclerosis \\
\hline & Multiple fractures & Multiple fractures of varying ages \\
\hline & & Sparing of the medullary cavities of long bones \\
\hline \multirow[t]{9}{*}{ Head and neck } & Large head with frontal and parietal bossing & Sclerotic calvarium and skull base \\
\hline & Hypoplastic facial bones with dysmorphic features & Hypoplastic facial bones, including mandible \\
\hline & & Incomplete pneumatisation of the paranasal sinuses \\
\hline & Persistent open anterior fontanelle & Persistent open anterior fontanelle \\
\hline & & Persistent open cranial sutures with wormian bones \\
\hline & Obtuse mandibular angle & Obtuse mandibular angle \\
\hline & Micrognathia & Micrognathia \\
\hline & Dental abnormalities & Dental abnormalities \\
\hline & Snoring and stridorous breathing & \\
\hline \multirow[t]{2}{*}{ Thorax } & Narrow chest & Aplastic acromion and/or distal clavicles \\
\hline & Pectus excavatum & \\
\hline \multirow[t]{5}{*}{ Spine and pelvis } & Kyphoscoliosis & Kyphoscoliosis \\
\hline & Increased lumbar lordosis & Increased lumbar lordosis \\
\hline & & Dense vertebral bodies with sparing of the transverse processes \\
\hline & & $\begin{array}{l}\text { Failure of complete segmentation of the atlas, axis and lower lumbar } \\
\text { vertebrae }\end{array}$ \\
\hline & & Spool-shaped vertebral bodies \\
\hline \multirow[t]{2}{*}{ Limbs } & Joint hypermobility & Widening of the distal femur \\
\hline & & Coxa valga \\
\hline \multirow[t]{3}{*}{ Extremities } & Broad hands and feet & Abnormal radio-ulnar articulation \\
\hline & Short fingers & $\begin{array}{l}\text { Acro-osteolysis (aplastic terminal phalanges with loss of ungual } \\
\text { tufts) }\end{array}$ \\
\hline & Dysplastic nails & \\
\hline
\end{tabular}

resulting from increased bone density and impaired bone vascularity. ${ }^{2}$ Cognitive functioning and life expectancy for pycnodysostosis sufferers is normal.

Several bone diseases should be considered in the differential diagnosis of pycnodysostosis, most importantly cleidocranial dysostosis, osteogenesis imperfecta and osteopetrosis. ${ }^{1,2}$ Cleidocranial dysostosis presents similarly to pycnodysostosis, with persistent open fontanelles and cranial sutures; however, it always involves the clavicle (a bone only rarely affected in pycnodysostosis $)^{1}$ and does not result in overall increased bone density. ${ }^{2}$ Osteogenesis imperfecta patients present with multiple fractures; however, these are more severe than in pycnodysostosis, and have associated features such as choanal atresia 


\section{CASE REPORT}

and blue sclera. ${ }^{1}$ Osteopetrosis also causes generalised osteosclerosis and increased bone density; however, the medullary cavities in the long bones are obliterated, and patients present with anaemia. Increased density of the skull base causes attenuation of foraminae, with resultant compression symptoms of the cranial nerves. ${ }^{2}$

Characteristic clinical and radiographic features of pycnodysostosis are summarized in Table $1 .^{1-6}$

The diagnosis is primarily based on the aforementioned clinical and radiographic features. However, a cathepsin $\mathrm{K}$ gene mutation analysis ${ }^{1,2}$ remains the gold standard confirmatory test.

No specific treatment options exist, so treatment is supportive, with fracture prevention and management constituting the most important aspects of clinical care. Dental hygiene and regular checkups are also helpful in preventing complications. ${ }^{1}$

\section{Conclusion}

Pycnodysostosis is a rare condition that is diagnosed primarily on its clinical and radiographic features. The importance of recognition of these features in the diagnosis and prevention of future complications is stressed in this case report.

1. Mujawar Q, Naganoor R, Patil H, Thobbi AN, Ukkali S, Malagi N. Pycnodysostosis with unusual findings: a case report. Cases Journal 2009;2:6544.

2. Hernandez-Alfaro F, Arenaz-Bua J, Serra Serrat M, Mareque Bueno J. Orthognathic surgery in pycnodysostosis: a case report. Int J Oral Maxillofac Surg 2011;40:106-123.

3. Stark Z, Savarirayan R. Review osteopetrosis. Orphanet Journal of Rare Diseases 2009;4:5.

4. Sutton D. Textbook of Radiology and Imaging. 7th ed. Kidlington, Oxford, UK: Churchill Livingstone, 2003:1123-1124.

5. Ihde LL, Forrester DM, Gottsegen CJ, et al. Sclerosing bone dysplasias: Review and differentiation from other causes of osteosclerosis. Radiographics 2011;31:1865-1882.

6. Ferreira Costa AL, De Castro Lopes SL, De Almeida SM, Steiner CE. Pycnodysostosis: An early case report with emphasis on the radiographic findings. Internet Journal of Dental Science 2006;3:2. 